\title{
LVI. The distribution in electric fields of the active deposits of radium, thorium, and actinium
}

\section{Sidney Russ}

To cite this article: Sidney Russ (1908) LVI. The distribution in electric fields of the active deposits of radium, thorium, and actinium , Philosophical Magazine Series 6, 15:89, 601-614, DOI: $10.1080 / 14786440809463802$

To link to this article: http://dx.doi.org/10.1080/14786440809463802

曲 Published online: 16 Apr 2009.

Submit your article to this journal $[\pi$

Џ Article views: 2

Q View related articles $\square$

Citing articles: 1 View citing articles 5 
duction. I have some plates made a year ago which show the bands most beautifully, but I have not yet enlarged them, and they are on too small a scale to reproduce well.

The present paper must not be regarded as a complete presentation of the subject,and I am publishing these results now in order that they may serve as a guide to those who are at work at the theory of the radiation of electron systems, from the theoretical side.

IVI. The Distritution in Electric Fields of the Active Deposits of Radium, Thorium, and Actinium. By Sidney Russ, Demonstrator of Physics, Victoria University, Manchester *.

\section{Introduction.}

T THE distribution in an electric field of the excited activity produced by thorium and radium emanations has been studied by several observers. Working with thorium emanation, Rutherford + has shown that the amount of activity imparted to a rod charged negatively decreases as the pressure in the containing vessel is reduced after a certain pressure is reached; while experiments made by Makower $\ddagger$ show that similar effects are obtained with the excited activity produced from radium emanation. Some further experiments by Rutherford $\S$ with the emanation from radium indicate that while at atmospheric pressure the greater part of the excited activity is directed to a cathode by moderate electric fields, yet a small fraction (about 5 per cent.) goes to an anode. Reasons are then (loc. cit.) given for supposing that some of the active deposit particles carry a negative charge, thus accounting for their transmission to the anode.

It seemed of interest then to find out whether the quantity of active deposit that goes to an anode changes when the pressure is varied.

A comparison has therefore been made over a range of pressure extending from $\cdot 001 \mathrm{~cm}$. to $10 \mathrm{cms}$. between the amount of activity imparted to a rod charged positively and then negatively when exposed for the same interval of time to equal quantities of the radium emanation.

It was found that whereas the activity of the cathode decreased as the pressure was diminished, the anode showed a corresponding increase in activity.

* Communicated by the Physical Society : read March 1.3, 1908.

† Rutherford, Phil. Mag. Feb. 1900.

† Makower, Phil. Mag. Nov. 1905.

§ Rutherford, Phil. Mag. Jan. 1903. 
602 Mr. S. Russ on Distribution in Electric Fields of

The rod which had served as cathode or anode was then made a neutral pole by connecting it to the containing vessel, and what may be called diffusion experiments, $i . e$. with no electric field existing in the gas, were then made. Observatious showed that there was a marked decrease in the amount of active deposit that diffused on to the rod as the pressure was diminished.

After a slight modification of the apparatus, a comparison of the activity obtained on a cathode and anode over a range of pressure extending from $\cdot 1 \mathrm{~mm}$. to $1 \mathrm{~mm}$. was made with three gases having widely different densities, namely, hydrogen, air, and sulphur dioxide.

The results in the case of air show that the activity of the cathode is considerably greater than that of the anode, but that they approach equality as the lower pressure is reached.

This effect is more marked in sulphur dioxide, while for hydrogen no such difference in activity is observed, just as much active deposit being transmitted to the anode as to the cathode over this range of pressure.

\section{Methods of Experiment.}

A comparison was first made between the amounts of excited activity obtained on a wire maintained at 200 volts acting as cathode and then as anode over a range of pressure extending from $\cdot 01 \mathrm{~mm}$. to $1 \cdot 2 \mathrm{~mm}$.

Fig. 1.

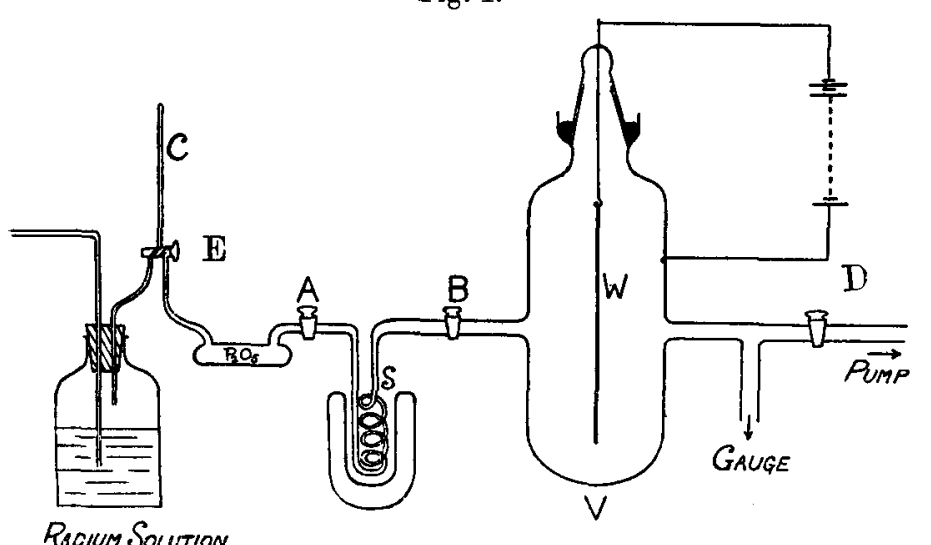

The apparatus used is represented in fig. 1. A brass wire W $10 \mathrm{cms}$. long, $55 \mathrm{~mm}$. diameter, on which the active 
Active Deposits of Radium, Thorium, and Actinium.

deposit was obtained, was suspended so as to hang symmetrically within the glass vessel V which was silvered on the inside, connexion to a battery of cells being made by means of a piece of platinum fused in the side of the vessel.

The usual method of experimenting was as follows:-

The whole system, with the exception of the vessel containing the radium emanation evolved from a solution of radium bromide, was exhausted firstly by means of a Fleuss pump and then by a charcoal tube immersed in liquid air (not shown in diagram). When the desired pressure had been obtained the tap D was closed, and by turning the tap $\mathrm{E}$ the small capillary tube C (.2 c.c. volume) was filled with the emanation at atmospheric pressure.

The tap B was then closed and the glass spiral S surrounded by liquid air, $\mathbf{E}$ was then turned and the emanation contained in the capillary $\mathrm{C}$ was allowed to pass over a tube containing $\mathrm{P}_{2} \mathrm{O}_{5}$ for drying purposes, after which it condensed in the spiral S.

A few trials showed that nearly all of the emanation had condensed in 15 minutes. The tap A was then closed, $B$ opened, the liquid air removed from the spiral, and the emanation allowed to diffuse into the vessel $V$ and a McLeod gauge which was in connexion with it. The resulting pressure was then read.

As the volume of the $\mathrm{P}_{2} \mathrm{O}_{5}$ tube was several times that of the spiral, quite low pressures were obtainable in the spiral although the capillary $\mathrm{C}$ had been filled at atmospheric pressures. The wire $\mathrm{W}$ was made either a cathode or anode as desired and exposed to the emanation for 1 hour. It was then removed from the vessel $V$, and its activity tested in the usual way by making it the central electrode of a cylinder connected with a Dolezalek electrometer and measuring the ionization produced by the $\alpha$ rays emitted from it. The electrometer leak obtained in a measured interval of time 14 minutes after the removal of the wire from the emanation. was taken as a measure of the activity obtained on the wire.

The variation in activity with change of pressure is seen from Table I., also from fig. 2, where the abscissæ represent pressures and the ordinates the corresponding activities of the wire. It will be seen from the diagram that there is a very large decrease in the activity of the cathode as the pressure is diminished, while the anode shows if anything a small increase; the amount obtained by diffusion alone, $i . e$. to a neutral rod, being practically constant over this range of pressure.

It will be observed that whereas at a pressure of about 
604 Mr. S. Russ on Distribution in Electric Fïlds of

TABLE 1 .

\begin{tabular}{|c|c|c|c|}
\hline \multicolumn{2}{|c|}{ Positive Electrode. } & \multicolumn{2}{|c|}{ NegativeíElectrode. } \\
\hline Pressure in mms. & Activity. & Pressure in $\mathrm{mms}$. & Activity. \\
\hline .011 & 69 & .006 & 142 \\
\hline \multirow[t]{3}{*}{$\cdot 013$} & 79 & $\cdot 008$ & 189 \\
\hline & 81 & $\cdot 102$ & 173 \\
\hline & & $\cdot 125$ & 157 \\
\hline '202 & 81 & 476 & 425 \\
\hline \multirow[t]{2}{*}{$\cdot 250$} & 62 & $\cdot 729$ & 736 \\
\hline & \multirow{2}{*}{63} & $1 \cdot 165$ & 1118 \\
\hline 608 & & \multicolumn{2}{|c|}{ Neutral Electrode. } \\
\hline 792 & $6 i$ & Pressure in mms. & Activity. \\
\hline$\cdot 865$ & 56 & $\cdot 15 \mathscr{Z}$ & 72 \\
\hline .922 & 56 & $\cdot 435$ & 64 \\
\hline \multirow[t]{2}{*}{$1 \cdot 102$} & \multirow[t]{2}{*}{57} & 722 & 57 \\
\hline & & $1 \cdot 140$ & 62 \\
\hline
\end{tabular}

$1 \mathrm{~mm}$. the activity of the cathode is about 20 times that of the anode, at $.01 \mathrm{~mm}$. it is only about twice as much.

At this stage of the work it was decided to compare the activities of the cathode and anode at much higher pressures.

Several trials with the apparatus just described were made at pressures higher than $1 \mathrm{~cm}$, but discordant results were obtained. This was probably due to the emanation being blown back into the spiral on allowing air to enter the vessel $\mathrm{V}$, which was initially well exhausted as in the previous experiments.

For this reason observations were made with a modified system consisting simply of a brass cylinder down the centre of which passed a brass rod (provided with end-pieces to ensure uniformity of field) which was connected to cells giving the same voltage as before. The brass cylinder was connected on one side with a small vessel which was filled with the emanation at atmospheric pressure, and on the other with a pump and pressure-gauge.

The small vessel containing the emanation was provided with metal electrodes, and the precaution was taken of applying a strong electric field to the emanation before letting it into the brass vessel; this removed any active deposit or dust particles. 
Active Deposits of Radium, Thorium, and Actinium. 605

Fig. 2.

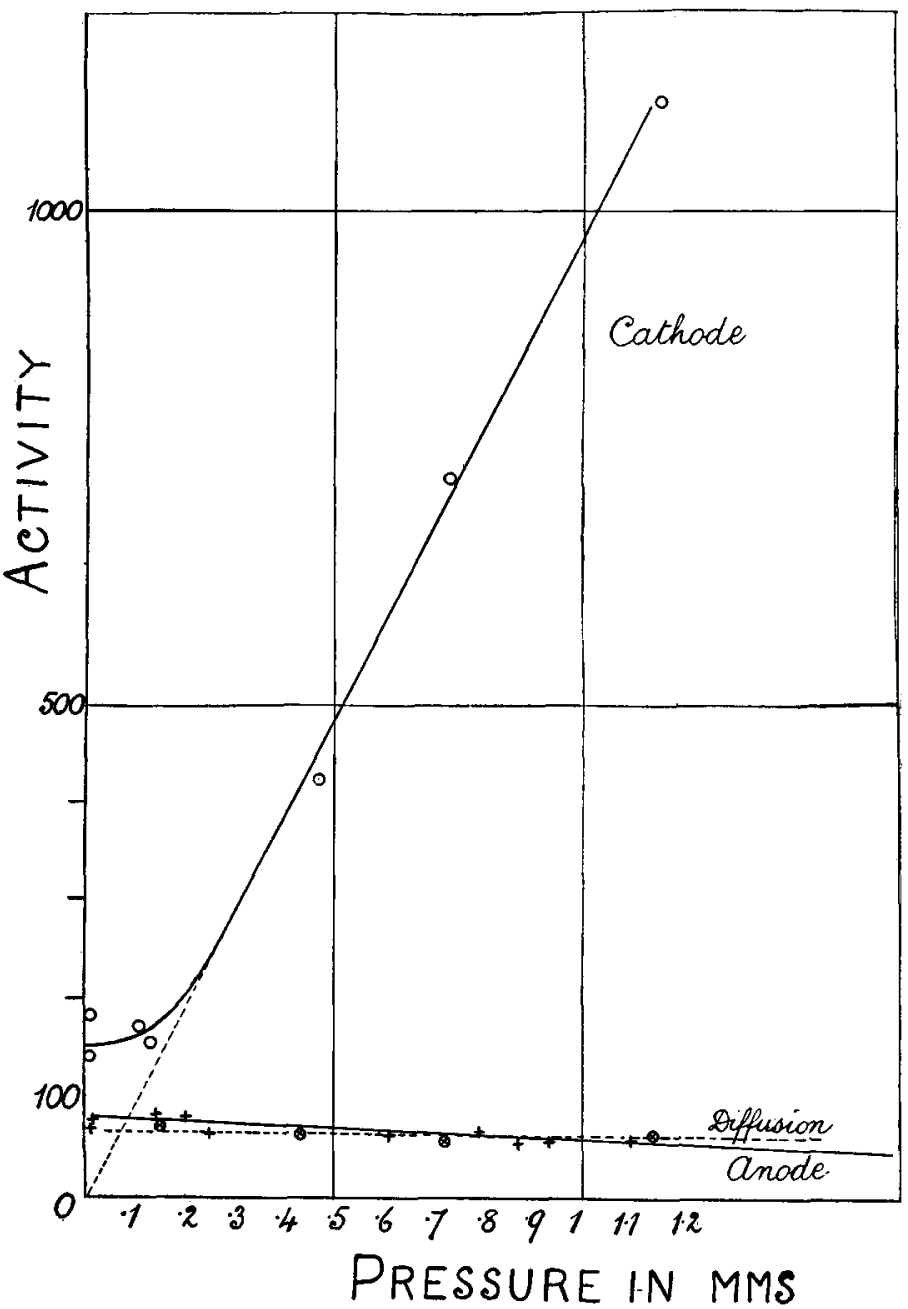

The system was initially exhausted to about $1 \mathrm{~mm}$. pressure, the emanation then let in and the small vessel isolated from the cylinder, the pressure in which was then adjusted to whatever value was required. The activity obtained on the brass rod after one hour's exposure was measured in exactly the same way as before. Observations were made for a range of pressure extending from $2 \mathrm{mms}$. to $10 \mathrm{cms}$. The numerical data are contained in Table II., and the results shown 
graphically in fig. 3, where abscissæ denote pressures and ordinates the corresponding activities.

TABLE II.

\begin{tabular}{|c|c|c|c|}
\hline \multicolumn{2}{|c|}{ Positive Electrode. } & \multicolumn{2}{c|}{ Negative Electrone. } \\
\hline Pressure in crs. & Activity. & Pressure in cms. & Activity, \\
\hline$\cdot 13$ & 152 & $\cdot 13$ & 780 \\
$\cdot 27$ & 140 & $2 \cdot 04$ & 1360 \\
$\cdot 55$ & 163 & $2 \cdot 70$ & 1400 \\
$\cdot 63$ & 148 & $7 \cdot 22$ & 1540 \\
$1 \cdot 10$ & 120 & $7 \cdot 80$ & 1470 \\
\cline { 2 - 4 } 3.78 & 94 & Pressure in cms. & Activity. \\
6.24 & 79 & $\cdot 36$ & 219 \\
7.30 & 77 & $\cdot 40$ & 198 \\
8.94 & 77 & $3 \cdot 14$ & 287 \\
10.96 & 75 & 3.74 & 300 \\
& & $8 \cdot 44$ & 447 \\
& & $8 \cdot 82$ & 437 \\
\hline
\end{tabular}

It will be seen that whereas the activity of the cathode decreases with diminishing pressure, there is a very marked increase in the activity of the anode, while the amount of active deposit that diffuses on to the neutral rod decreases very considerably as the pressure is reduced.

Diffusion experiments similar to those just cited are at present being made, in which, however, other metals than brass are used as containing-cylinder and rod.

It will be seen from fig. 3 that at a pressure of about $2 \mathrm{mms}$. the quantity of active deposit transmitted to the anode is approximately equal to that diffusing on to a neutral pole.

Now the active deposit that diffuses on to a neutral pole we have seen to be in the main positively charged (the bulk of it going to a cathode in an electric field). Very little of this positively charged matter can make its way to the anode. In order to account for the quantity obtained on the anode we are led to the conclusion that some at least of the active deposit particles that make their way to the anode are negatively charged. 
Active Deposits of Radium, Thorium, and Actinium. 607

The above results then go to confirm the view held by Rutherford already referred to, that the active deposit particles which are directed to the anode have a negative charge.

Fig. 3.

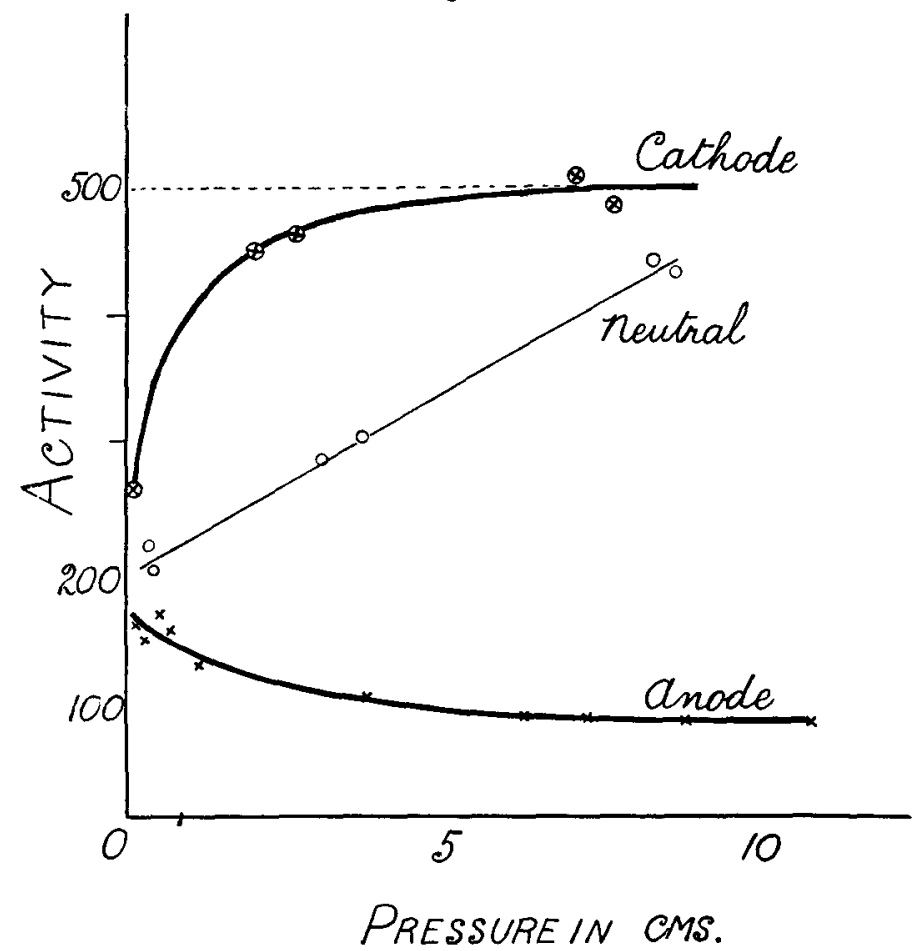

'The activity of the cathode being much larger than the anode, the scale in fig. 3 for the cathode is one third that for the anode and neutral pole.

It has been suggested by Rutherford *, in explanation of his results with thorium emanation, that the decrease in activity of the cathode as the pressure is reduced is due to a decreasing number of collisions between the active deposit particles and the gaseous molecules with which they are mixed.

At the moment of expulsion of an $\alpha$ particle from the emanation atom, the residue, $i$. $e$. the active deposit particle, acquires a velocity in the opposite direction, which, though

$$
\text { * 'Radioactivity,' p. } 319 .
$$


608 Mr. S. Russ on Distribution in Electric Fields of

small compared with that of the $\alpha$ particle, is high compared with the velocity of an ordinary gaseous molecule.

On the view above cited a certain number of collisions with the gas molecules is necessary to sufficiently reduce the velocity of the active deposit particles in order that moderate electric fields may direct them to cathode or anode.

Hence we might expect the effectiveness of a molecular encounter to depend on the nature of the gaseons molecules with which the active matter is associated. Experiments to test this point were therefore made with three gases differing considerably in molecular constitution, namely, air, hydrogen, and sulphur dioxide, and a comparison between the activities of cathode and anode over a range of pressure extending from $1 \mathrm{~mm}$. to $1 \mathrm{~mm}$. was made with the low pressure system already described. The silvered ressel was,

Fig. 4.

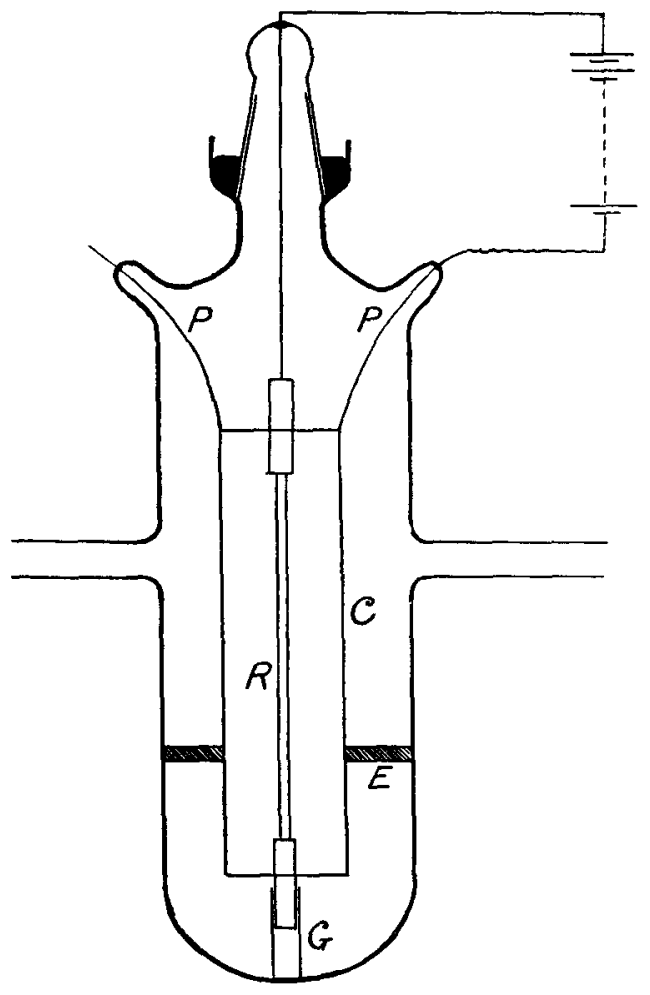

however, replaced by another glass vessel containing two concentric cylinders as seen in fig. 4 . 
Active Deposits of Radium, Thorium, and Actinium. 609

The inner one $\mathrm{R}, 7 \mathrm{cms}$. long and $\cdot 36 \mathrm{~cm}$. diameter, acted as the rod upon which the active deposit was obtained, $\mathrm{C}$ the outside cylinder, $8.95 \mathrm{cms}$. long and $2.7 \mathrm{cms}$. diameter, being suspended by two platinum wires $P P$ which were sealed into the glass vessel and connected to either pole of the battery as required. The ebonite ring $\mathrm{E}$ kept the outer cylinder steady, and the rod $R$ was supplied with a guard-ring at each end, one of which fitted into a glass tube $G$, thus serving to keep the rod central within the cylinder C.

These modifications were adopted so as to ensure a uniform electric field between the rod and cylinder, and also to render the problem more accessible to mathematical treatment, the areas of the rod and cylinder being not very different. With this arrangement experiments with the gases already mentioned were made, and the results obtained are collected in Table III. and reproduced graphically in figs. 5 and 6 .

TABLE III.

\begin{tabular}{|c|c|c|c|c|c|}
\hline \multicolumn{3}{|c|}{ AIr. } & \multicolumn{3}{|c|}{ Sulpilur Dioxide. } \\
\hline $\begin{array}{l}\text { Sign of } \\
\text { Electrode. }\end{array}$ & $\begin{array}{c}\text { Pressure } \\
\text { in mms. }\end{array}$ & Activity. & $\begin{array}{c}\text { Sign of } \\
\text { Electrode. }\end{array}$ & $\begin{array}{l}\text { Pressure } \\
\text { in mms. }\end{array}$ & Activity. \\
\hline \multirow{6}{*}{$\begin{array}{c}\text { Positive. } \\
\text { " } \\
\text { " } \\
\text { Negative. } \\
\text { ", }\end{array}$} & $\cdot 115$ & 108 & Positive. & 302 & 111 \\
\hline & $\cdot 185$ & 122 & , & $1 \cdot 120$ & 93 \\
\hline & $\cdot 931$ & 95 & ", & $\ldots$ & $\ldots$ \\
\hline & $\cdot 115$ & 146 & Negative. & .297 & 148 \\
\hline & $\cdot 260$ & 137 & , & $\cdot 462$ & 184 \\
\hline & .902 & 211 & , & $\cdot 970$ & 298 \\
\hline & \multicolumn{4}{|c|}{ HYDROGEN. } & \\
\hline & \multicolumn{2}{|c|}{$\begin{array}{l}\text { Sign of } \\
\text { Electrode. }\end{array}$} & $\begin{array}{l}\text { Pressure in } \\
\text { wms. }\end{array}$ & Activity. & \\
\hline & \multicolumn{2}{|c|}{$\begin{array}{c}\text { Positive. } \\
", \\
"\end{array}$} & $\begin{array}{l}.084 \\
.481 \\
.828\end{array}$ & $\begin{array}{l}184 \\
200 \\
194\end{array}$ & \\
\hline & Neg & tive. & $\begin{array}{r}\cdot 116 \\
\cdot 131 \\
\cdot 462 \\
.925 \\
\cdot 970 \\
1 \cdot 050\end{array}$ & $\begin{array}{l}212 \\
198 \\
192 \\
202 \\
239 \\
188\end{array}$ & \\
\hline
\end{tabular}


610 Mr. S. Russ on Distribution in Electric Fields of

It will be seen that for $\mathrm{SO}_{2}$ there is a much greater difference in the activities of cathode and anode than is the case for air, while for bydrogen practicully no difference in activity oyer the same range of pressure was obtained.

Fig. 5.

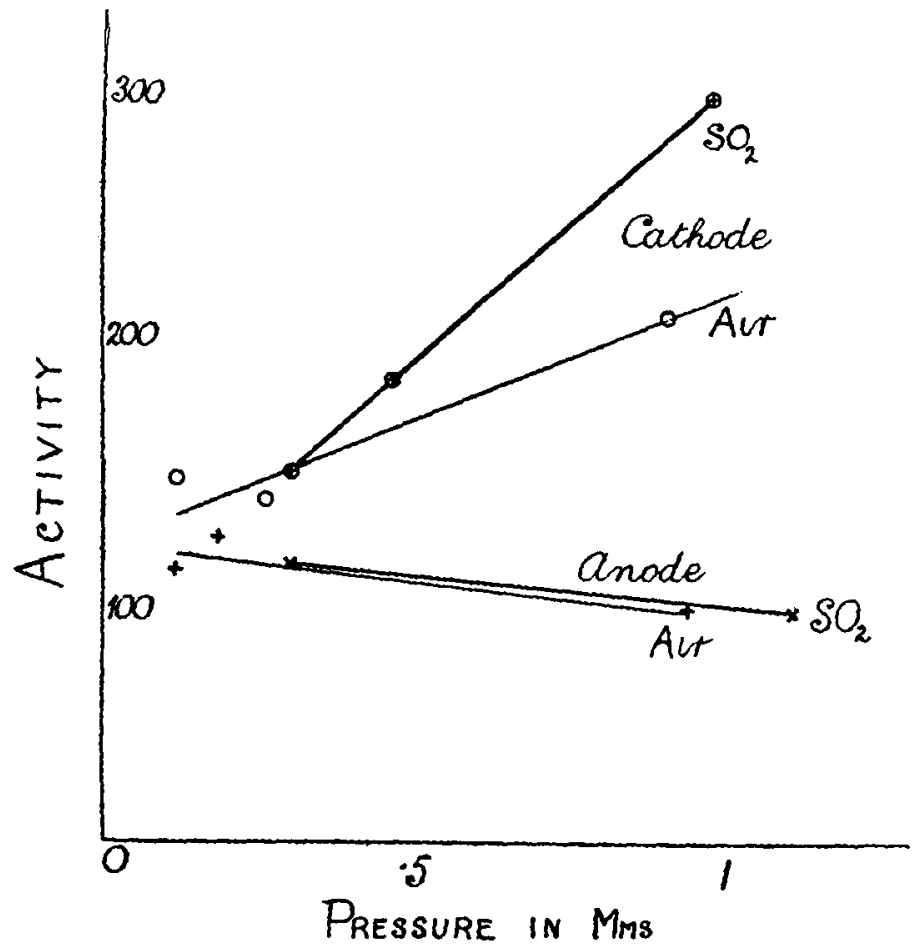

We should expect that the curves for cathode and anode in the case of hydrogen would show a divergence at higher pressures, for if an encounter between the active deposit particle and a hydrogen molecule is not so effective in reducing the velocity of the former as a sulphur dioxide molecule, then we shall require a higher pressure with hydrogen to observe the eame effects as with sulphur dioxide. 
Active Deposits of Radium, Thorium, and Actinium. 611 Fig. 6.

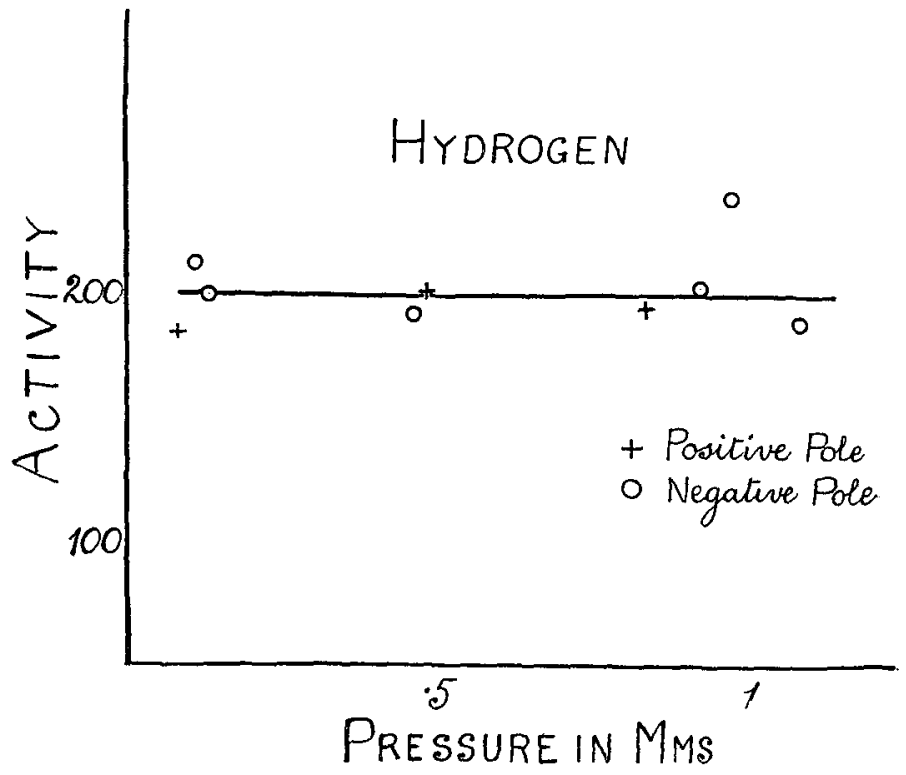

Thorium and Actinium.

A few experiments made with the emanations from thorium and actinium show a rather striking difference in the distribution of their active deposits in an electric field.

The experimental arrangement seen in fig. 7 was used.

Fig. 7.

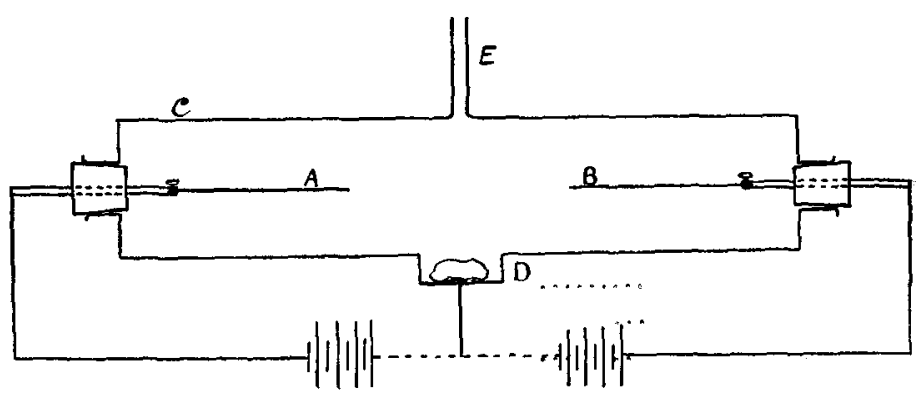

Two thin brass wires $7.5 \mathrm{cms}$. long and $7 \mathrm{~mm}$. diameter were made to lie along the axis of a brass tube $\mathrm{C} 30 \mathrm{cms}$. long and $4.2 \mathrm{cms}$. diameter. This tube was fitted with a small capsule $\mathrm{D}$, into which was placed a small quantity of 
thorium oxide, or of a preparation of actinium kindly lent me by Professor Rutherford.

The wire $A$ was connected to the positive, $B$ to the negative pole of a battery giving 320 volts, the brass tube being connected to the middle point.

The exit-tube $\mathrm{E}$ was connected to a Fleuss pump and a set of tubes containing calcium chloride and cotton-wool, thus ensuring a supply of dry and dust-free air.

When experimenting with thorium the wires were exposed to the emanation for 24 hours, alter which they were removed and their activities tested with an electrometer in the manner already described.

The ratio of the activities of the cathode and anode at atmospheric pressure was found to be about $200: 1$; on reducing the pressure to $2 \mathrm{mms}$. the ratio was diminished to $25: 1$, this reduction being mainly due to the decrease in activity of the cathode already observed by Rutherford (loc. cit.). No certain increase in the very small activity of the anode was observed.

In the experiments with actinium the wires were exposed usually for about 2 hours.

At atmospheric pressures the ratio of the activities of the cathode and anode was about 2 to 1 , while at $2 \mathrm{~mm}$. pressure it was 22 to 1 , the increase in the ratio being mostly due to an increase in the activity of the cathode. The active deposit on the two wires decayed at the same rate, namely, that of actinium $A$.

These results show that while the greater part of the active deposit from actinium emanation has a positive charge, yet at amospheric pressure a very considerable fraction has a negative charge, and is therefore directed to the anode.

For purposes of comparison the activities obtained on a wire when exposed to the emanations of $\mathrm{Ra}, \mathrm{Th}$, and $\mathrm{Ac}$ at atmospheric pressure are tabulated.

$\begin{array}{lccc}\text { Thorium } & \ldots . . . . & \begin{array}{c}\text { Wire charged } \\ \text { negatively. }\end{array} & \begin{array}{c}\text { Wire charged } \\ \text { positively. }\end{array} \\ \text { Radium } & \ldots . \ldots . . . & 200 & 1 \\ \text { Actinium } & \ldots . . . . . & 200 & 10 \\ & & & 100\end{array}$

\section{Conclusion.}

In view of the different distributions in an electric field of the active deposits of thorium, radium, and actinium, it is difficult to think of the whole series of events between the 
Active Deposits of Radium,Thorium, and Actinium. 613

formation of the active deposit and its transference to either electrode, as taking place in an exactly similar fashion.

It has been shown by Miss Slater* that slowly moving $\beta$ particles accompany the $\alpha$ particles which are ejected from thorium and radium emanations. If there are two such $\beta$ particles to every $\alpha$ particle, the remainder of the emanation atom, i.e. the active deposit, would be left with a positive charge.

This supposition would explain the almost complete transference of the active deposit of thorium to the cathode: but the small, though quite definite, quantity of the active deposit of radium that is directed to the anode still presents a difficulty. It may be that a few of the active deposit particles gain negative ions from the gas in which they are moving, which must be present in very large numbers.

In the case of actinium, although at a pressure of a few millims., far more astivity is observed on the cathode than on the anode, as has already been found by Debiernet, yet we have seen that at higher pressures this inequality is very much reduced, there being almost as many negative carriers as positive.

It is hoped that a more extended series of observations may throw some light on the apparently anomalous behaviour of actinium.

In conclusion, I desire to thank Professor Rutherford for several suggestions during the latter part of the work. The research was begun with Mr. Makower, who, however, could not continue the collaboration owing to pressure of other work. I wish to express my thanks for the very considerable help he has given me in these experiments.

\section{Note added March 17 th.}

Some recent experiments made with actinium tend to explain the anomalous behaviour referred to ahove. A preparation of actinium was placed at the bottom of a cylinder, and two parallel plates were suspended so as to hang vertically above it. These plates were connected to the terminals of a battery of 300 volts, and after an exposure at atmospheric pressure usually lasting several hours the activities of the two plates were compared by means of an electroscope. The distance of the plates from the actinium preparation could be altered as required.

* Phil. Mag. Oct. 1905.

+ Comptes Rendus, vol. esxxvi. p. 671.

Phil. Mag. S. 6. Vol. 15. No. 89. May 1908. 


\section{Prof. R. A. Lehfeldt on the Electrochemical}

As already observed in the experiments described, the activity of the cathode was always greater than that of the anode.

It was found that when the plates were fixed at a distance of $4 \mathrm{cms}$. from the actinium, the ratio of the activity of the cathode to that of the anode was about 5 to 1 ; on bringing the plates nearer to the actinium this ratio rapidly increased, and when the distance was reduced to $2 \mathrm{mms}$. the activity of the cathode was more than a hundred times that of the anode.

These observations and others of a similar nature at different pressures (details of which it is hoped will appear in a future number), indicate that the sign of the electrical charge exhibited by the active deposit particles is some function of the distance which they have travelled through the containing gas, before reaching the electrodes.

LVII. The Electrochemical Equivalents of Oxygen and Hydrogen. By R. A. LeHFeldt, D.Sc., Professor of Physics at the Transvaal University College*.

THE present investigation is an attempt $(a)$ to design a 1 gas-coulometer (voltameter) suitable for exact measurement; (b) to find how far the electrolysis of various solutions gives the calculated yield of gas ; (c) to use the instrument to determine the electrochemical equivalents of oxygen and hydrogen.

In its general design the coulometer follows the accepted methods of gas-analysis.

\section{Description of Apparatus.}

The coulometer itself is shown in fig. 1. It is made entirely of glass. The tnbe $A$, in which the electrolysis takes place, is about $22 \mathrm{~mm}$. diam. and 70 long. It is closed below by a rubber stopper B carrying the electrodes $\mathrm{C}$ and $\mathrm{D}$ and the inverted thermometer $\mathrm{E}$. The electrodes are of platinum, usually about 3 sq. cms. each, welded to platinum wires which are sealed through the glass tubes. The tubes are about half a millimetre in internal diameter, with an enlargement at the top where the platinum wire is sealed through; they can consequently hold mercury even when inverted, and current can be led in and out by means of copper wires (No. 30 gauge) pushed up from below.

The thermometer $\mathrm{E}$ is required for the temperature of the

* Communicated by the Author. 